\title{
Manejo clínico odontológico integral del paciente con síndrome de Sjögren: Una propuesta
}

\section{Integral dental clinical management of patients with Sjögren's syndrome: A proposal}

\author{
Sturla Rojas $\mathrm{G}^{*}$, Romo Ormazábal F*,**, Torres-Quintana MA*,***
}

\section{RESUMEN}

El síndrome de Sjögren (SS) es una enfermedad autoinmune, crónica e inflamatoria caracterizada por infiltración de células plasmáticas y linfocitos en las glándulas exocrinas, particularmente en las salivales y oculares. La patogénesis del SS está relacionada con factores inmunológicos, neurológicos, genéticos, virales y hormonales. La deficiente calidad y cantidad de saliva trae consecuencias devastadoras para la salud dental y bucal, alteraciones del esmalte, caries en las superficies dentarias expuestas, principalmente cervicales, fallas en la adhesión de los materiales obturadores, queratosis en las mucosas, síndrome de boca urente y disconfort en el uso de prótesis dentarias, a pesar de un manejo exhaustivo del medio bucal. Un diagnóstico tardío del SS conlleva a graves consecuencias físicas, sicológicas y económicas en estos pacientes. Su diagnóstico y tratamiento son de gran interés para el odontólogo. La experiencia clínica señala que aquellas piezas dentarias restauradas con prótesis fijas tienen mayor sobrevida y la rehabilitación con prótesis implantosoportadas brindaría un mayor confort para los pacientes. La clínica odontológica debe tener un enfoque integral del daño y la forma de tratamiento debe considerarlos como pacientes de muy alto riesgo de caries basados en CAMBRA (Caries management by risk assesement). El manejo eficaz de la salud oral en estos pacientes comprende la mejora de la producción salival, preservación de mucosas orales y la evaluación periódica del estado bucal. Se propone un protocolo de atención odontológica integral que consta de tres fases: 1) Fase inicial, paliativa y preventiva; 2) Fase restauradora y rehabilitadora, y 3) Fase de mantenimiento.

Palabras clave: Síndrome de Sjögren, síndrome Sicca, xerostomia, fracaso de la restauración dental.

\section{SUMMARY}

Sjögren's syndrome (SS) is an autoimmune, chronic and inflammatory disease characterized by infiltration of plasma cells and lymphocytes in the exocrine glands. The pathogenesis of SS is related to immune, neurological, genetic, viral and hormonal factors. Complications are related to glandular destruction and mucosal dryness. The poor quality and quantity of saliva brings devastating consequences to dental and oral health. Alterations in the enamel structure, constant presence of caries in tooth surfaces exposed, mainly cervical, failures in the adhesion of filling materials, keratoses on the mucous membranes, burning mouth syndrome and discomfort in the use of dentures, despite the exhaustive management of the oral environment, are described. A late diagnosis of SS leads to serious physical, psychological and economic consequences in these patients. Its diagnosis and treatment are of great interest to the dentist. Clinical experience indicates that those teeth restored with fixed prostheses have an improved survival and rehabilitation with implant-supported prostheses would provide greater comfort for patients. The dental clinic must have a comprehensive approach to injury and the form of treatment should be considered as patients at high risk of caries based on CAMBRA (Caries 
management by risk assesement). Effective management of oral health in these patients includes improving the production of saliva, oral mucosal preservation and regular assessment of oral status. A comprehensive dental care protocol consisting of three phases, is proposed: 1) Initial, palliative and preventive phase, 2) Restorative and rehabilitation phase, and 3) Maintenance phase.

Key words: Sjögren's syndrome, Sicca syndrome, xerostomia, dental restoration failure.

Fecha de recepción: 22 de febrero 2011.

Aceptado para publicación: 10 de marzo de 2011.

Sturla Rojas G, Romo Ormazábal F, Torres-Quintana MA. Manejo clínico odontológico integral del paciente con síndrome de Sjögren: Una propuesta. Av. Odontoestomatol 2014; 30 (4): 205-217.

\section{INTRODUCCIÓN}

Los importantes cambios en los sistemas de salud han conmovido a la comunidad, la movilización demográfica y la forma de presentación de la enfermedad, han influido notablemente en la toma de decisiones respecto a las intervenciones en odontología. Los avances biotecnológicos, la aparición de nuevos métodos diagnósticos y las nuevas posibilidades terapéuticas en rehabilitación oral, tales como implantología, regeneración tisular inducida por biomateriales y terapia génica, le han dado un nuevo poder a las ciencias biológicas que han impactado en la odontología y están cambiando la naturaleza de la práctica odontológica (1). En este aspecto, el manejo de la salud bucal de un paciente con síndrome de Sjögren puede ser un modelo para la práctica odontológica integral, con una base más amplia de conocimientos en biología y medicina (2).

El síndrome de Sjögren (SS) es una enfermedad inflamatoria crónica, epitelitis autoinmune, caracterizada por la infiltración de las glándulas exocrinas por linfocitos (principalmente LT-CD4+) y células plasmáticas, los cuales están implicados en la destrucción del parénquima glandular (3). Por ello las principales manifestaciones de este trastorno son disfunciones de las glándulas salivales y lagrimales, y sequedad generalizada de las mucosas $(2,4)$.

El diagnóstico y tratamiento odontológico de pacientes con SS es de gran interés para el odontólogo, ya que en muchas ocasiones es el primero en enfrentar clínicamente los signos y síntomas de la enfermedad, asociados con los cambios en el medio bucal dada la falta del fluido salival. La visión tradicional respecto al "cuidado dental" debería ampliarse al observar la patología bucal múltiple presentada por los pacientes afectados por este síndrome. El diagnóstico precoz, la atención y el cuidado óptimo de los pacientes con síndrome de SS, requieren de un reconocimiento integral de esta condición por el odontólogo general, quien a su vez debe estar involucrado en un equipo multidisciplinario de salud médica $(2,4)$.

\section{DESARROLLO}

\section{MANIFESTACIONES CLÍNICAS}

El SS es una de las exocrinopatías autoinmunes más comunes, con una prevalencia estimada de más de 1 millón de personas en los Estados Unidos (2). Cuando las manifestaciones clínicas se limitan sólo a las glándulas exocrinas, principalmente glándulas salivales y lagrimales, la condición se considera SS primario, en asociación a otra enfermedad inmunológica se considera SS secundario. El SS se describe como una enfermedad cuya manifestación primaria se puede extender entre un $0,05 \%$ a $1 \%$ de la población, y en su forma secundaria, acompaña al $30 \%$ de los pacientes con artritis reumatoidea, $10 \%$ de los que tienen lupus y $20 \%$ de los que presentan esclerodermia $(5,6)$. Se ha reportado además un alto riesgo de desarrollar linfoma maligno en pacientes con SS primario (4). Es por esto que, en todo paciente en el que se presente clínicamente un SS, debe buscarse otra enfermedad reumatológica. Se espera una manifestación del 3 al 5\% en la población geriátrica. 
La prevalencia es mayor en mujeres en una proporción de 9:1 respecto a los hombres, presentándose generalmente después de los 40 años (7-9), sin embargo también se ha descrito una forma de SS primario juvenil, en niños y adolescentes $(10,11)$, los cuales presentan signos más severos de la enfer$\operatorname{mad}(5)$.

La participación de las glándulas exocrinas en el SS no se limita sólo a las salivales y lagrimales, también puede implicar a las glándulas del aparato respiratorio, gastrointestinal, vaginal y piel. Las glándulas productoras de mucus del árbol respiratorio pueden estar también comprometidas lo que resulta en sequedad de la nariz, garganta y tráquea. En el tracto gastrointestinal aparece atrofia de la mucosa esofágica, gastritis atrófica o pancreatitis subclínica (12). En genitales externos, las enfermas refieren dispareunia. El $60 \%$ de los pacientes pueden tener además manifestaciones extraglandulares, comprometiendo por infiltración linfoide a los pulmones, riñones, hígado, sistema nervioso, vasos sanguíneos, articulaciones, músculos o transformarse en una enfermedad proliferativa de linfocitos $\mathrm{B}(2,8)$. Los pacientes también pueden presentar lesiones cutáneas como púrpura hipergammaglobulinémico, que además puede acompañarse de neuropatías periféricas. Junto con el SS, los individuos experimentan otras enfermedades como fibromialgia, migraña, fenómeno de Raynaud e hipotiroidismo (9).

Los signos más frecuentes del SS son: la queratoconjuntivitis sicca (por disminución de la secreción lacrimal) y las manifestaciones bucales (por disminución de la secreción salival). En la mayoría de los pacientes, las glándulas parótidas o las submaxilares están levemente aumentadas de tamaño, firmes e indoloras; esto principalmente en pacientes con SS primario (8). La saliva tiene aspecto espumoso, espeso y no se observa una acumulación de ésta en el piso de boca. La mucosa oral se ve seca, pegajosa y a veces ulcerada. La lengua se presenta roja, seca, depapilada y fisurada, y en algunos casos con atrofia de las papilas filiformes (Fig.1) (2,13). Estas características de las mucosas y la falta de saliva determinan en estos pacientes pérdida del gusto y un alto riesgo de infecciones recurrentes por cándida, a menudo asociado a síndrome de boca urente $(14,15)$. Aumenta también la incidencia de

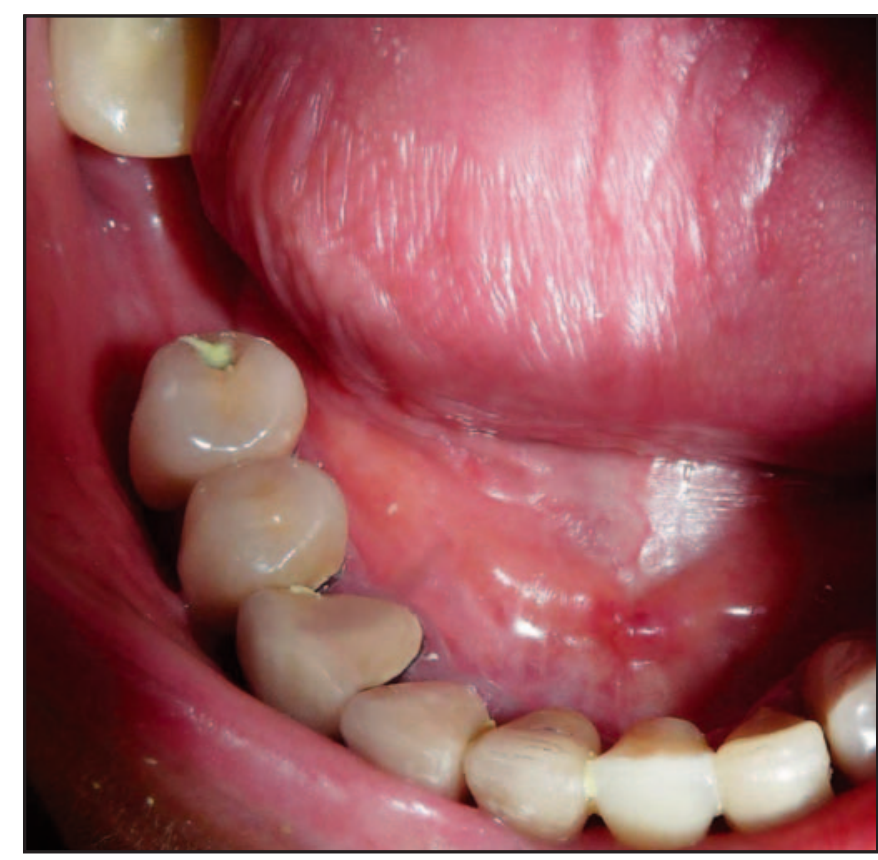

Fig. 1. Hiposialia en piso de boca y lengua depapilada.

caries y su severidad, presentando principalmente caries cervicales y en casos severos se encuentran rodeando el cuello de los dientes, sobre todo en los dientes anteroinferiores (Fig. 2). También se describen caries en las superficies incisales en casos severos incluso en presencia de buena higiene bucal (2). La xerostomía o sensación de boca seca resulta ser uno de los principales síntomas en el SS por disminución de la secreción salival, incluso algunos pacientes expresan boca urente, dificultad para masticar, disfagia con los alimentos secos, dificultad para hablar y disgeusia o cambios en la percepción del gusto $(2,3,16)$.

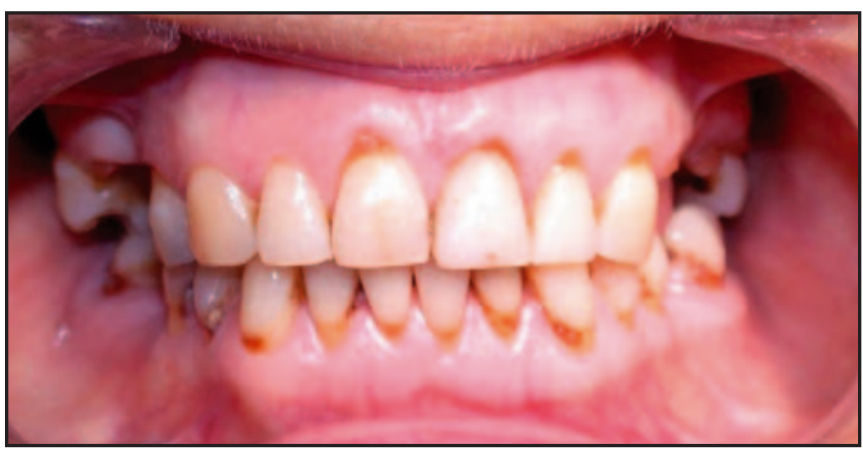

Fig. 2. Múltiples caries cervicales. 


\section{DIAGNÓSTICO}

En toda historia clínica, el odontólogo debería indagar respecto a Xerostomía o dificultades para tragar. Un diagnóstico precoz del SS puede ser fundamental, ya que en muchas ocasiones tiene un progreso lento, transcurriendo desde el primer síntoma hasta la expresión plenamente sintomática de la enfermedad y el diagnóstico definitivo entre 8 a 10 años (2). Un test inicial de flujo salival (sialometría) realizado en la consulta odontológica resulta ser un buen indicador de disfunción glandular (sin estimulación, por expectoración simple o por test de Schirmer modificado, o sialometría estimulada por masticación de parafina), sin embargo únicamente este examen no puede diagnosticar SS. Se han propuesto además de la sialometría, la sialoquímica (espectro electroforético, SELDITOF-MS) pues son exámenes simples, seguros (no invasivos) y sensibles (detección temprana de la enfermedad) y han mostrado que la concentración total de proteínas salivales está extremadamente aumentado en la saliva de los pacientes con SS $(9,17)$. Sin embargo, no hay un criterio de diagnóstico universalmente aceptado para el diagnóstico de SS lo que ha llevado a confusión tanto en la investigación clínica como en la práctica (13). El diagnóstico resulta com- plejo pues debe incluir evaluación del componente ocular y salival y también una diferenciación entre SS primario y secundario. Los pacientes con SS secundario presentan elevados niveles de proteína $C$ reactiva en el plasma, no así los con SS primario (8).

Actualmente no hay un criterio de clasificación globalmente aceptado para SS y se usa la versión de los criterios diagnósticos desarrollados por el Grupo de Consenso Americano-Europeo del 2002 (Tabla 1) $(18,19)$, que considera la evaluación de signos y síntomas bucales, signos y síntomas oculares, histopatología de biopsia de glándulas salivales labiales, y la presencia de anticuerpos séricos antinucleares (ANA): anticuerpos anti-Ro o SS-A y anti-La o SS-B $(13,18$, 19) y se ha sugerido que pacientes con SS tendrían una expresión reducida de IgA y aumentada de IgG en células plasmáticas (20).

Entre estos criterios hay dos que son objetivos, el IV y el VI y obligatorios, uno de los cuales debe estar presente para diagnosticar SS primario. El diagnóstico definitivo de SS se realiza cuando: a) 4 de los 6 ítems evaluados están presentes, uno de los cuales es el IV o el VI; o b) presencia de tres de cualquiera de los cuatro criterios objetivos III, IV, V o VI.

\section{TABLA 1.- CRITERIOS DIAGNÓSTICOS PARA EL SÍNDROME DE SJOGREN REVISADOS POR EL GRUPO DE CONSENSO AMERICANO-EUROPEO DEL 2002}

\begin{tabular}{|c|c|}
\hline I. Síntomas oculares & $\begin{array}{l}\text { - ¿Ha presentado ojo seco a diario por más de } 3 \text { meses? } \\
\text { - ¿Tiene sensación de arenilla ocular a repetición? } \\
\text { - ¿Usa lágrimas artificiales } 3 \text { o más veces en el día? }\end{array}$ \\
\hline II. Síntomas orales & $\begin{array}{l}\text { - ¿Siente la boca seca diariamente por más de tres meses? } \\
\text { - ¿Se le han hinchado las parótidas siendo adulto? } \\
\text { - ¿Necesita beber para tragar alimentos secos? }\end{array}$ \\
\hline III. Signos oculares & $\begin{array}{l}\text { - Prueba de Schimer ( } 5 \text { mm o menos en } 5 \text { min). } \\
\text { - Prueba rosa de bengala (puntaje de } 4 \text { o mayor a 4). }\end{array}$ \\
\hline IV. Hallazgos histopatológicos & $\begin{array}{l}\text { En la biopsia de glándula salivar menor, la presencia de más de } \\
1 \text { foco (<50 células) de células mononucleares por } 4 \mathrm{~mm}^{2} \text { de } \\
\text { tejido glandular. }\end{array}$ \\
\hline $\begin{array}{l}\text { V. Compromiso objetivo de glándulas } \\
\text { salivales }\end{array}$ & $\begin{array}{l}\text { - Por cintigrafía parotídea o por sialografía parotídea o sialometría } \\
\text { sin estimulación menos de } 1,5 \mathrm{ml} \text { o menos en } 15 \text { min. }\end{array}$ \\
\hline VI. Autoanticuerpos & - Positividad de: Ro (SSA) o La (SSB) o AAN o FR. \\
\hline
\end{tabular}




\section{ETIOPATOGENIA}

La mayoría de las enfermedades del tejido conectivo involucran la tríada de: autoinmunidad, susceptibilidad genética y desencadenante ambiental. En el SS, aparecen estos tres factores pero, además, se involucra una relación compleja entre ellos con la aparición de otros potenciales factores contribuyentes, tales como: factores neurológicos, virales y hormonales $(8,13,20)$.

Básicamente se describen cuatro eventos comunes en todos los pacientes con SS:

1. El inicio por un factor exógeno,

2. Alteración de las células epiteliales de la glándula salival,

3. La migración de los linfocitos T-CD4+ y la infiltración linfocitaria de las glándulas exocrinas, salivales, lagrimales, y otras.

4. La formación de estructuras tipo centros germinales que contienen células dendríticas foliculares (DC), células B proliferantes e hiperreactividad de esos linfocitos B con la producción de factor reumatoide y anticuerpos Ro (SS-A) y La (SS-B) $(4,5)$.

Un modelo para la patogénesis de SS sugiere dos fases, una no inmune y otra inmune. En la fase no inmune, una anormalidad genética de base o una infección viral desencadenaría la apoptosis de las células epiteliales glandulares y los restos celulares fagocitados podrían actuar como autoantígenos, provocando una respuesta inmune. En la fase inmune, a niveles molecular y celular, las células epiteliales tienen un papel importante tanto en su iniciación como en la perpetuación de las lesiones autoinmunes. La presentación del antígeno, la apoptosis, la producción de chemoquinas y metaloproteasas o la formación de centros germinales se encuentran en el centro de la patogénesis de los SS, todo orquestado por las células epiteliales (21). Las alteraciones en una serie de mediadores inmunes contribuyen a la desregulación crónica inmune. Estos cambios incluyen: sobreexpresión de los genes reguladores del interferón I, expresión anormal del factor activador de células $B$, y la activación de la vía celular interleucina-23-T-helper tipo 17 (4). Este proceso inflamatorio inmune-mediato dañaría además las glándulas de otros órganos $(8,13,20)$.
Algunas investigaciones actuales sugieren que la patogénesis inmune del SS estaría mediada por el sistema nervioso $(13,22,23)$. Este mecanismo de desarrollo neural-autoinmune mediato de la enfermedad se basa en el hecho de que la función salival normal depende de la activación nerviosa de la glándula. Nervios eferentes colinérgicos que liberan acetilcolina inducen el lagrimeo y la salivación por estimulación muscarínica de receptores M3 de las glándulas lacrimales y salivales. Estos receptores serían bloqueados por la inmunoglobulina $\mathrm{G}$ de pacientes con SS primario, como ha sido demostrado en experimentaciones en ratas, impidiendo la activación de las glándulas para la producción de su secreción.

La predisposición genética para el desarrollo del SS estaría relacionada con la observación de que pacientes con historia familiar del síndrome, presentan antígenos leucocitarios específicos y tienen un mayor riesgo de desarrollar la enfermedad. Esto podría estar asociado con polimorfismos de genes del complejo mayor de histocompatibilidad pero se requiere una mayor investigación en esta área para establecer una asociación definitiva $(5,13)$.

La evidencia actual que involucra virus específicos en este síndrome es conflictiva, sugiriéndose que los virus pueden promover la producción de autoanticuerpos a través de mimetismo molecular, dando lugar a una reacción cruzada de reactivos inmunes con los antígenos del huésped (5). Algunos de los virus que han sido implicados en el desarrollo de SS son citomegalovirus, virus Epstein-Barr, virus hepatitis $\mathrm{C}$, leucemia de células-T humanas/virus-1, linfoma y VIH $(13,24)$.

El hecho de que SS ocurre más a menudo en mujeres que en hombres sugiere el posible rol de las hormonas sexuales en la patogénesis de la enfermedad. La relación entre andrógenos y estrógenos regula la respuesta inmune, los estrógenos estimulan al sistema inmune controlando el crecimiento linfocitario, su diferenciación, proliferación, presentación de antígenos, producción de citoquinas, de anticuerpos, sobrevivencia celular y apoptosis. Los estrógenos disminuyen durante la menopausia y es cuando más susceptibles son las mujeres a desarrollar SS sugiriendo que, ya sea la reducción de estrógenos o la diferencia en la relación entre andrógenos y estró- 
genos, estaría involucrado en el inicio de la enfermedad (5).

Entre las enfermedades autoinmunes, el SS muestra la mayor incidencia de trastornos linfoproliferativos malignos y se ha observado que la presencia de un severo ataque de las glándulas exocrinas, de vasculitis, de niveles bajos de $\mathrm{C} 4$ y crioglobulinemia, al momento del diagnóstico, identifica específicamente a los pacientes con SS que presentan alto riesgo de desarrollar linfoma y por lo tanto altas tasas de mortalidad (4).

\section{DISFUNCIÓN SALIVAL: CONSECUENCIAS EN EL MEDIO BUCAL Y LA TERAPÉUTICA REHABILITADORA}

La saliva desempeña un papel importante en el mantenimiento y protección de la salud bucal y una deficiente calidad y cantidad de saliva puede tener consecuencias muy perjudiciales (3). La saliva es importante para la masticación, la deglución, la digestión, para la percepción del sabor y el habla, también es fundamental para la mantención de los tejidos blandos y duros de la cavidad bucal y en el control de poblaciones microbianas que coexisten en nichos bucales $(2,25,26)$.

El flujo salival facilita el movimiento de la lengua, mucosa y labios, ayudando en la limpieza de la boca arrastrando restos de comida y bacterias, permitiendo el movimiento de la lengua y los labios necesarios para la fonación. También contribuye a la formación y transporte del bolo alimenticio permitiendo la deglución. Enzimas digestivas, como la amilasa y lipasa, están presentes en la saliva y participan en la digestión. La saliva también ayuda a proteger el tracto gastrointestinal superior por su acción buffer. Glicoproteínas salivales (mucinas) se unen a la superficie de las células epiteliales uniendo con gran afinidad moléculas de agua, manteniendo la hidratación de las superficies mucosas. Algunos factores de crecimiento de la saliva (EGF) estimulan la proliferación y la regeneración del epitelio. Además contiene varios antimicrobianos que ayudan a mantener la flora bucal normal incluyendo: inmunoglobulina secretora A, lactoferrina, lisozima y lactoperoxidasa. La proteína histatina, potente antifúngico con propiedades antibacterianas, se encuentra únicamente en la saliva $(2,26)$.
La saliva también es importante para los dientes. En boca, se produce un proceso continuo de desmineralización y remineralización donde la saliva actúa como un factor dinamizador de este equilibrio inclinándolo hacia la remineralización $(27,28)$. Las concentraciones salivales de calcio y fósforo, se mantienen sobresaturadas como resultado de proteínas específicas de la saliva (estaterina y proteínas ricas en prolina). Además, la capacidad buffer de la saliva, como resultado de la presencia de bicarbonato y de iones fosfato, así como de histatina, ayuda a mantener el $\mathrm{pH}$ relativamente neutro (26). Los pacientes que poseen poca producción de saliva presentan un medio bucal ácido por ausencia de la capacidad amortiguadora frente a la producción ácida de las bacterias y la falta de una concentración sobresaturada de calcio y fósforo favorece la desmineralización del esmalte, generando puntos en los tejidos dentarios altamente susceptibles para la adhesión bacteriana y desarrollo de múltiples potenciales procesos cariosos, aumentando así el proceso de desmineralización. La xerostomía secundaria a SS reduce el contenido de proteínas IgA, lo que debilita el sistema de defensa antibacteriano contra la caries (29). Esto determina además los fracasos en la adhesión de biomateriales restauradores a los dientes. En el caso de las resinas compuestas, la contracción de polimerización genera fuerzas acumuladas en las estructuras cristalinas del esmalte y la dentina, debilitadas dada la tendencia a la desmineralización asociada a la deficiente calidad de la saliva; esto genera microfracturas marginales que inducen el desalojo de la restauración y/o la aparición de nuevas caries (Fig. 3). Respecto al vidrio ionómero, su adhesión a la superficie dentaria falla al perder su integridad marginal por deshidratación, desalojándose o desintegrándose (30). Las amalgamas parecen ser una excelente opción cuando el flujo salival esta disminuido, dado su bajo coeficiente de expansión, y su alta resistencia a la compresión, indisolubilidad y resistencia marginal. Sin embargo la destrucción coronaria observada en estos pacientes es muy extensa en las superficies vestibulares y linguales limitando su utilización por biomecánica y estética (31).

La reducción del flujo salival determina un elevado riesgo de desarrollar nuevas lesiones cariosas $(32,33)$ y los pacientes presentan un alto índice de pérdida de piezas dentarias por caries (2). El nivel de riesgo 


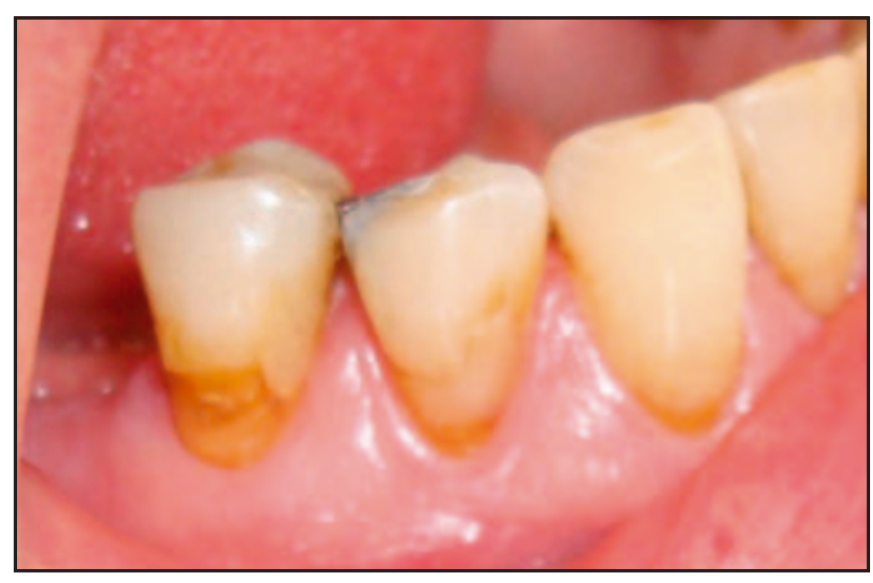

Fig. 3. Desalojo de restauración y restauración defectuosa después de 6 meses de longevidad.

determina los procedimientos diagnósticos y los riesgos en el tratamiento. En este aspecto, las recomendaciones realizadas por el Grupo Consenso "Caries Management By Risk Assesement" (CAMBRA) para el tratamiento en niños de 6 años y más pueden ser usadas con éxito en este tipo de pacientes (Tabla 2) $(32,34)$.

El alto riesgo a desarrollar nuevas lesiones cariosas en pacientes con SS dificulta la indicación de una terapia restauradora y hasta ahora no existe evidencia que determine cuál sería la mejor elección. En caso de rehabilitación con prótesis fija (PF), se ha sugerido evitar las ferulizaciones y la prótesis fija plural, que puede causar un cambio en la microflora bucal y dificultar aún más la mantención de una adecuada higiene bucal (27). En caso de rehabilitación con prótesis fija unitaria algunos autores han sugerido realizar terminaciones cervicales supragingivales para facilitar la higiene y la observación de la integridad marginal en el tiempo (35), pero dado el alto índice de caries es mejor proteger estas zonas realizando terminaciones cervicales intracreviculares. Se ha descrito la rehabilitación de pacientes desdentados parciales mediante prótesis parcial removible (PPR), las prótesis con dentosoporte presentarían mejor pronóstico que una prótesis dentomucosoportada, dado el rol fundamental de la saliva en la generación de una capa húmeda en la superficie mucosa que aumenta la tensión superficial de las bases contribuyendo a la retención de las prótesis mucosoportadas. La queja más común de pacientes con xerostomía es la sensación de que los alimentos se quedan adheridos a la superficie y debajo de las bases protésicas (36). El paciente con SS que utilice PPR debe ser muy riguroso con su higiene bucal, y el dentista en el control de las superficies dentarias relacionadas con los retenedores y superficies protésicas evitando lesiones de la mucosa oral. La rehabilitación mediante prótesis totales (PT), es extremadamente inconfortable para los pacientes con SS, la reducción del flujo salival causa síndrome de boca urente, erosión en la mucosa, dificultad para masticar y deglutir lo que determina el rechazo a la utilización de PT. Sin embargo, en pacientes que no tengan otra posibilidad terapéutica el uso de paliativos se hace indispensable para el uso de PT, tales como aceite de manzanilla (Matricaria chamomilla $L$ ), y enjuagues frecuentes de infusión de llantén (Plantago major $L$ ), matico (Buddleja globosa Hope) y manzanilla (medicina herbolaria) Algunos autores han reportado éxito a largo plazo de la rehabilitación de maxilares totalmente desdentados de pacientes con SS mediante el uso de prótesis implanto soportadas tales como las prótesis híbridas similares a las prótesis Ad-Modum Branemark $(16,37)$.

Actualmente no se cuenta con tratamiento curativo para el SS, se trata principalmente de atenuar los síntomas. Para los ojos secos se recomienda el uso de lágrimas artificiales. Evitar los climas secos, vivir en zonas de humedad relativamente baja, sin polvo ni humo. Los agonistas muscarínicos como el clorhidrato de pilocarpina (38) y clorhidrato de cevimelina, pueden ser usados para tratar ojos y boca seca. Estudios recientes comprueban la efectividad del clorhidrato de pilocarpina y recomiendan sus usos en dosis entre $20 \mathrm{mg}$ diarios (tabletas de $5 \mathrm{mg}, 4$ veces al día) (39) y $30 \mathrm{mg}$ diarios (2,5 mg a $5 \mathrm{mg}$, de 2 a 6 veces al día) (38). Para el clorhidrato de cevimelina con dosis de $30 \mathrm{mg}$, 3 veces al día, se obtendrían mejoras significativas en los síntomas de resequedad del SS, además de ser bien toleradas (40), con incremento en el fluido salival y en la concentración de amilasa salival y de IgA (41). Otros estudios usando INF-alfa con dosis por vía oral de 150 UI 3 veces al día, a pacientes con SS primario obtuvieron un incremento en el flujo de saliva no estimulada y mejoras en los síntomas de xerostomía y xeroftalmía, sin efectos adversos de importancia y buena tolerancia de los pacientes al medicamento $(42,43)$. 


\section{TABLA 2.- "CARIES MANAGEMENT BY RISK ASSESSMENT" CAMBRA: GUÍA CLÍNICA PARA PACIENTES DE 6 AÑOS O MÁS (JENSON L. 2007)}

\begin{tabular}{|c|c|c|c|c|c|c|c|c|}
\hline $\begin{array}{l}\text { Nivel de } \\
\text { riesgo }\end{array}$ & $\begin{array}{l}\text { Frecuencia } \\
\text { radiográfica }\end{array}$ & $\begin{array}{l}\text { Frecuencia de } \\
\text { cariograma }\end{array}$ & $\begin{array}{l}\text { Test de saliva } \\
\text { (flujo y cultivo } \\
\text { bacteriano) }\end{array}$ & $\begin{array}{l}\text { Antibacterianos } \\
\text { (clorhexidina, } \\
\text { xilitol) }\end{array}$ & Fluoruros & Control de $\mathrm{Ph}$ & $\begin{array}{l}\text { Suplementos } \\
\text { de potasio y } \\
\text { calcio }\end{array}$ & $\begin{array}{l}\text { Sellantes (en } \\
\text { base a resina } \\
\text { o vidrio ionó- } \\
\text { mero) }\end{array}$ \\
\hline Bajo & $\begin{array}{l}\text { Radiografía } \\
\text { Bitewing } \\
\text { cada 24-36 } \\
\text { meses. }\end{array}$ & $\begin{array}{l}\text { Reevaluación de } \\
\text { riesgo cariogé- } \\
\text { nico cada 6-12 } \\
\text { meses. }\end{array}$ & $\begin{array}{l}\text { Quizás como } \\
\text { línea base de } \\
\text { referencia en } \\
\text { pacientes } \\
\text { nuevos. }\end{array}$ & $\begin{array}{l}\text { Según lo } \\
\text { arrojado por el } \\
\text { test de saliva. }\end{array}$ & $\begin{array}{l}\text { Pasta de dientes con } \\
\text { contenido de flúor } 2 \\
\text { veces al día, después } \\
\text { del desayuno y en la } \\
\text { noche al acostarse. } \\
\text { Opcionalmente barniz } \\
\text { de NaF si hay exposi- } \\
\text { ción excesiva de la raíz } \\
\text { o sensibilidad. }\end{array}$ & No requiere & $\begin{array}{l}\text { No requeri- } \\
\text { do. Opcional } \\
\text { en excesiva } \\
\text { exposición } \\
\text { radicular o } \\
\text { sensibilidad }\end{array}$ & $\begin{array}{l}\text { Opcional o } \\
\text { como el } \\
\text { protocolo de } \\
\text { sellantes } \\
\text { ICDAS }\end{array}$ \\
\hline Moderado & $\begin{array}{l}\text { Radiografía } \\
\text { Bitewing } \\
\text { cada 18-24 } \\
\text { meses. }\end{array}$ & $\begin{array}{l}\text { Reevaluación } \\
\text { de riesgo cario- } \\
\text { génico cada 4- } \\
6 \text { meses. }\end{array}$ & $\begin{array}{l}\text { Quizás como lí- } \\
\text { nea base de re- } \\
\text { ferencia en pa- } \\
\text { cientes nuevos } \\
\text { o si se sospecha } \\
\text { de un alto re- } \\
\text { cuento bacteria- } \\
\text { no y para eva- } \\
\text { luar la eficacia y } \\
\text { cooperación del } \\
\text { paciente. }\end{array}$ & $\begin{array}{l}\text { Según lo arrojado } \\
\text { por el test de sali- } \\
\text { va. } \\
\text { Xilitol (6-10 gr/día) } \\
\text { chicles o mastica- } \\
\text { bles (2 o } 4 \text { veces } \\
\text { al día). }\end{array}$ & $\begin{array}{l}\text { Pasta de dientes con } \\
\text { contenido de flúor } 2 \\
\text { veces al día. Enjua- } \\
\text { gue de NaF al } 0,05 \% \\
\text { diariamente. } 1-2 \text { apli- } \\
\text { caciones iniciales de } \\
\text { barniz de NaF, otra } \\
\text { aplicación a los } 4-6 \\
\text { meses. }\end{array}$ & No requiere & $\begin{array}{l}\text { No requeri- } \\
\text { do. Opcional } \\
\text { en excesiva } \\
\text { exposición } \\
\text { radicular o } \\
\text { sensibilidad }\end{array}$ & \begin{tabular}{|l|} 
Según \\
protocolo de \\
sellantes \\
ICDAS
\end{tabular} \\
\hline Alto & $\begin{array}{l}\text { Radiografía } \\
\text { Bitewing } \\
\text { cada 6-18 } \\
\text { meses o } \\
\text { hasta que } \\
\text { las lesiones } \\
\text { no cavita- } \\
\text { das sean } \\
\text { evidentes. }\end{array}$ & $\begin{array}{l}\text { Reevaluación } \\
\text { de riesgo } \\
\text { cariogénico } \\
\text { cada 3-4 } \\
\text { meses y } \\
\text { aplicación de } \\
\text { barniz de } \\
\text { fluoruro. }\end{array}$ & $\begin{array}{l}\text { Test de flujo sali- } \\
\text { val y cultivo bac- } \\
\text { teriano inicial- } \\
\text { mente y cada } \\
\text { vez realizado el } \\
\text { cariograma para } \\
\text { evaluar la efica- } \\
\text { cia y colabora- } \\
\text { ción del pacien- } \\
\text { te. }\end{array}$ & $\begin{array}{l}\text { Gluconato de clor- } \\
\text { hexidina al } 0,12 \% . \\
\text { Enjuague con } 10 \\
\text { ml por } 1 \text { minuto } \\
\text { al día durante una } \\
\text { semana cada mes. } \\
\text { Xilitol (6-10 gr/día) } \\
\text { chicles o mastica- } \\
\text { bles (dos, } 4 \text { veces } \\
\text { al día). }\end{array}$ & $\begin{array}{l}\text { Pasta de dientes alta- } \\
\text { mente fluorada (1,1\% } \\
\text { NaF) } 2 \text { veces al día en } \\
\text { vez de la pasta de dien- } \\
\text { tes fluorada regular. } \\
\text { Opcionalmente enjua- } \\
\text { gue de NaF al } 0,2 \% \\
\text { diariamente ( } 1 \text { bote- } \\
\text { lla), luego enjuague } \\
\text { bucal de NaF al } 0,05 \% \\
2 \text { veces al día. } 1-3 \text { apli- } \\
\text { caciones iniciales de } \\
\text { barniz de NaF, otra apli- } \\
\text { cación a los } 3-4 \text { meses. }\end{array}$ & No requiere & $\begin{array}{l}\text { Opcional: } \\
\text { aplicación de } \\
\text { pasta calcio/ } \\
\text { fosfato varias } \\
\text { veces al día }\end{array}$ & \begin{tabular}{|l|} 
Según \\
protocolo de \\
sellantes \\
ICDAS
\end{tabular} \\
\hline
\end{tabular}

La presencia de candida bucal puede ser tratada con aplicación bucal tópica de clotrimazol o nistatina y la anfotericina B puede ser recomendada en casos refractarios. Muchas indicaciones respecto a la higiene bucal, cepillado frecuente de los dientes, uso del hilo dental, uso de antisépticos orales como la clorhexidina y revisiones periódicas con el odontólogo para tratamientos de higiene bucal y aplicaciones tópicas de flúor, tipo de alimentación no cariogénica, mucha hidratación con una frecuencia de 8 a 10 vasos diarios y uso de elementos remineralizadores de las superficies dentarias $(8,44)$. Se reco- 
mienda también el uso Saliva Artificial y otros Humectantes Bucales $(38,45)$.

\section{PROTOCOLO DE MANEJO CLÍNICO ODONTOLÓGICO INTEGRAL DEL PACIENTE CON SÍNDROME DE SJÖGREN}

En la literatura, se ha propuesto un manejo odontológico para estos pacientes basado en prevención de caries, tratamiento de candidiasis, estimulación del flujo salival y uso de sustitutos salivales. Sin embargo, basándose en la observación y seguimiento de pacientes con SS que acuden a la Clínica Odontológica del Adulto de la Facultad de Odontología de la U. de Chile, se ha considerado que el tratamiento odontológico integral de estos pacientes es más amplio y se deben tener consideraciones especiales con ellos antes, durante y después de todo el tratamiento. Es por esto que se propone un plan de tratamiento odontológico integral de pacientes con síndrome de Sjögren, basado en CAMBRA, considerando a estos pacientes como de alto riesgo de caries y con condiciones especiales. El manejo y seguimiento clínico de pacientes con este síndrome, puede manejarse en tres fases:

1. Fase inicial, paliativa y preventiva.

2. Fase restauradora y rehabilitadora.

3. Fase de mantención.

\section{Fase inicial, paliativa y preventiva}

Explicar, advertir y tranquilizar al paciente sobre las repercusiones bucales de su enfermedad sistémica. Controlar dieta indicando reducción de carbohidratos y disminuir horas de ingesta (máximo 4 veces al día).

\section{Tratamiento paliativo}

Se trata de estimular el flujo salival, indicando gomas de mascar y caramelos sin azúcar, abundante ingesta de agua (mínimo 2 litros repartido en 8 a 10 vasos diarios). También se pueden indicar sustitutos de saliva, pero sus beneficios son limitados y de breve duración, aunque puede ser de ayuda para pacientes con úlceras orales o erosiones (13). El uso de pilocarpina y cevimelina no es de fácil acceso por lo que no fueron incluidos en el protocolo.

\section{Asesoría preventiva}

Manejo antibacteriano con antisépticos como Gluconato de clorhexidina al $0,12 \%, 10 \mathrm{ml}$ de enjuague durante un minuto diariamente por una semana cada mes y no usando pastas dentales con monofluorofosfato de sodio $(46,47)$ durante el periodo de una hora debido a que la inactiva. Mascar chicles de xilitol (Orbit $\left.{ }^{\circledR}\right)$. Indicación de enjuagues con solución de bicarbonato de sodio después de comer para mantener $\mathrm{pH}$ y enjuague con infusión de manzanilla para estimular la reparación de mucosas. En caso necesario, realizar tratamiento periodontal, que incluye destartraje supragingival y pulido coronario; y, en periodontitis, destartraje subgingival y pulido radicular en sacos activos.

\section{Exodoncias de piezas con mal pronóstico}

En estos pacientes se debe evitar realizar tratamientos en piezas dentarias con pronóstico dudoso o malo.

\section{Motivación e instrucción de higiene}

Usando pasta de dientes fluorada (2.500-5.000 ppm) de uso matutino y nocturno dejándola en boca o bien aplicándola con una cubetilla plástica para uso nocturno; además, indicación de colutorio de flúor $0,05 \%$ + cloruro de cetilpiridinio para uso diario o cada vez que sienta la boca seca y uso diario de seda dental fluorada. En la consulta, aplicación de barniz de flúor (22.600 ppm), inicialmente 1-3 aplicaciones en un mes y otra aplicación a los 3 meses (32,34, 48 ). Aplicar sellantes en surcos profundos.

\section{Fase restauradora y rehabilitadora}

Restaurar caries cervicales recientes, de preferencia con amalgamas

Si está comprometida la estética utilizar resina o vidrio ionómero y evaluar su integridad en controles 
sistemáticos cada tres meses. Si las restauraciones cervicales fracasan constantemente, evaluar la posibilidad de acceder al tratamiento con PFU para evitar la excesiva pérdida dentaria por caries o como se ha frecuentemente observado, la obliteración por calcificación de los conductos radiculares. Si no es posible, realizar restauraciones en forma transitoria cubriendo las superficies dentarias en espera de un tratamiento más definitivo, sin olvidar los controles periódicos.

\section{Aplicar tratamiento definitivo}

Rehabilitar con PF las piezas dentarias con caries cervicales extensas o en aquellas en que las restauraciones cervicales han fracasado 2 o más veces en el periodo de 2 años (Fig 4). Teniendo extremo cuidado en el control la flora bacteriana cariogénica instaurando enjuagatorios con soluciones antisépticas una semana por mes permanentemente. En el caso de SS avanzado, se ha observado obliteración de conductos radiculares, en ese caso, se recomienda no insistir en la endodoncia y realizar corona periférica sin sistema de perno muñón. Preferir rehabilitar espacios edéntulos con prótesis fija sobre implantes en vez de prótesis removibles. Rehabilitar con PPR dentosoportadas sólo en caso estrictamente necesario y en caso de desdentamiento total preferir prótesis implantosoportadas a prótesis totales mucosoportadas que inducen mayores alteraciones en las mucosas y aumentan el riesgo de sobreinfección con cándidas.

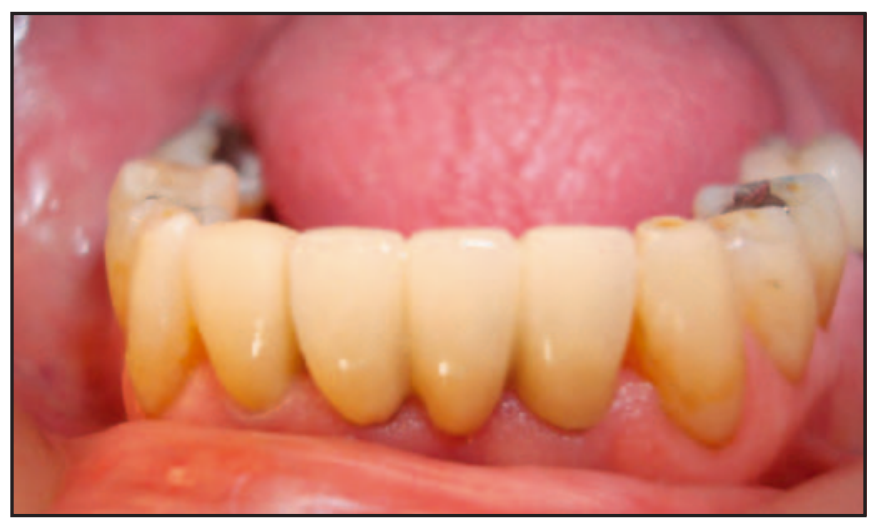

Fig. 4. Rehabilitación con prótesis fija en piezas dentarias cuyas restauraciones de resina compuesta o vidrio ionómero han presentado longevidad inferior a un año, protege los tejidos dentarios del medio bucal mostrando mayor longevidad.

\section{Fase de mantención}

Cada 3 meses realizar control clínico, con cariograma, aplicación de barniz de flúor, controlar dieta, higiene bucal, estado periodontal, estado de restauraciones y prótesis, y controlar estado de cámaras y conductos pulpares por análisis radiográfico.

\section{CONCLUSIONES}

El SS es una de las enfermedades crónicas sistémicas autoinmunes más frecuentes, caracterizada por sequedad de las mucosas oculares y de la cavidad bucal por exocrinopatía y destrucción del parénquima de glándulas lagrimales y salivales. Aunque su etiología exacta permanece aún en estudio su manejo terapéutico requiere de un equipo multidisciplinario de salud donde el odontólogo juega un papel fundamental, ya que los pacientes presentan manifestaciones orales que requieren un manejo odontológico especial. El conocimiento de esta enfermedad es clave en el éxito del tratamiento por el odontólogo, quien actualmente fracasa en su labor por fallas en el diagnóstico oportuno y desconocimiento acerca de un protocolo de tratamiento. El tratamiento debe ser integral, y se han descrito numerosas formas en que el odontólogo puede desempeñar un papel más activo en la gestión global de los pacientes con síndrome de Sjögren.

Se concluye de esta revisión la necesidad de utilizar un protocolo de tratamiento específico en estos pacientes para aumentar la tasa de éxito en el tratamiento. Se presenta un protocolo de tratamiento odontológico integral considerando el riesgo cariogénico de estos pacientes según CAMBRA asignándoles la categoría de "Muy alto riesgo de caries y con condiciones especiales". Este protocolo de tratamiento presenta tres fases:

- Una fase inicial, paliativa y preventiva.

- Una fase restauradora y rehabilitadora y

- Una fase de mantenimiento.

Del protocolo de tratamiento se concluyen las siguientes medidas:

1. En casos de caries cervicales es recomendable restaurar con amalgamas, siempre y cuando sea viable en cuanto a la adhesión macromecánica y no afecte la estética del paciente. 
Sturla Rojas G, Romo Ormazábal F, Torres-Quintana MA.

2. Aunque el enfoque terapéutico debería tender a la conservación del remanente dentario, el uso de prótesis fijas unitarias que cubran los tejidos dentarios protegiéndolos del medio bucal ha mostrado una mayor longevidad que las restauraciones de resina compuesta y vidrio ionómero.

3. Los tratamientos con pronóstico dudoso o malo no deben ser aplicados en estos pacientes.

4. En caso de pérdida del remanente dentario la terapia indicada seria implantosoportada.

5. La temprana intervención del odontólogo, puede prevenir la obliteración de los conductos radiculares que podrían tener relación con una forma de defensa dentinopulpar según el tiempo de desarrollo de la enfermedad, y la aparición de lesiones cariosas.

6. El manejo del medio bucal y los controles seriados, son fundamentales para la mantención de la longevidad de las piezas dentarias y restauraciones fijas así como el control infeccioso de la enfermedad, brindando, de esta forma, una mejor calidad de vida a estos pacientes.

\section{BIBLIOGRAFÍA}

1. Hunt RJ, Bushong M. ADEA CCI vision focuses on preparing graduates for discoveries of the future. J Dent Educ 2010;74(8):819-23.

2. Mathews SA, Kurien BT, Scofield RH. Oral manifestations of Sjögren's syndrome. J Dent Res 2008;87(4):308-18.

3. Soto-Rojas AE, Kraus A. The oral side of Sjögren syndrome. Diagnosis and treatment. A review. Arch Med Res 2002;33(2):95-106.

4. Voulgarelis M, Tzioufas AG. Pathogenetic mechanisms in the initiation and perpetuation of Sjögren's syndrome. Nat Rev Rheumatol 2010;6(9):529-37.

5. Bayetto K, Logan RM. Sjögren's syndrome: a review of aetiology, pathogenesis, diagnosis and management. Aust Dent J 2010;55(Suppl 1):3947.

6. Margaix-Muñoz M, Bagán JV, Poveda R, Jiménez Y, Sarrión G. Sjögren's syndrome of the oral cavity.
Review and update. Med Oral Patol Oral Cir Bucal 2009;14(7):E325-30.

7. Bacman S, Berra A, Sterin-Borda L, Borda E. Muscarinic acetylcholine receptor antibodies as a new marker of dry eye Sjögren syndrome. Invest Ophthalmol Vis Sci 2001;42(2):321-7.

8. Hammi AR, Al-Hashimi IH, Nunn ME, Zipp M. Assessment of SS-A and SS-B in parotid saliva of patients with Sjögren's syndrome. J Oral Pathol Med 2005;34(4):198-203.

9. Tomiita M, Takei S, Kuwada N, Nonaka Y, Saito K, Shimojo $N$, et al. Efficacy and safety of orally administered pilocarpine hydrochloride for patients with juvenile-onset Sjögren's syndrome. Mod Rheumatol 2010;20(5):486-90.

10. Ostuni PA, Ianniello A, Sfriso P, Mazzola G, Andretta M, Gambari PF. Juvenile onset of primary Sjögren's syndrome: report of 10 cases. Clin Exp Rheumatol 1996;14(6):689-93.

11. Hamburger J. Sjögren's syndrome - managing oral and systemic symptoms via a multi-disciplinary approach. Oral Dis 2004;10(5):306-9.

12. Al-Hashimi. I. The management of Sjögren's syndrome in dental practice. J Am Dent Assoc 2001;132:1409-17.

13. Guinn AC, Rouleau TS, Brennan MT. Burning tongue and lips. Diagnosis: Sjögren syndrome with concurrent candidal infection. J Am Dent Assoc 2010;141(5):541-5.

14. Ergun S, Cekici A, Topcuoglu N, Migliari DA, Külekçi G, Tanyeri H, et al. Oral status and Candida colonization in patients with Sjögren's Syndrome. Med Oral Patol Oral Cir Bucal 2010;15(2):e310-5.

15. Binon PP. Thirteen-year follow-up of a mandibular implant-supported fixed complete denture in a patient with Sjögren's syndrome: a clinical report. J Prosthet Dent 2005;94(5):409-13.

16. Kalk WW, Vissink A, Stegenga B, Bootsma H, Nieuw Amerongen AV, Kallenberg CG. Sialometry 
and sialochemistry: a non-invasive approach for diagnosing Sjögren's syndrome. Ann Rheum Dis 2002;61(2):137-44.

17. Vitali C, Bombardieri S, Jonsson R, Moutsopoulos HM, Alexander EL, Carsons SE, et al. European Study Group on Classification Criteria for Sjögren's Syndrome. Classification criteria for Sjögren's syndrome: a revised version of the European criteria proposed by the American-European Consensus Group. Ann Rheum Dis 2002;61(6):554-8.

18. Langegger C, Wenger M, Duftner C, Dejaco C, Baldissera I, Moncayo R, et al. Use of the European preliminary criteria, the Breiman-classification tree and the American-European criteria for diagnosis of primary Sjögren's Syndrome in daily practice: a retrospective analysis. Rheumatol Int 2007;27(8): 699-702.

19. Salomonsson S, Rozell BL, Heimburger M, Wahren-Herlenius M. Minor salivarygland immunohistology in the diagnosis of primary Sjögren's syndrome. J Oral. Pathol Med 2009;38(3):282-8.

20. Goicovich E, Molina C, Pérez P, Aguilera S, Fernández J, Olea $\mathrm{N}$ et al. Enhanced degradation of proteins of the basal lamina and stroma by matrix metalloproteinases from the salivary glands of Sjögren's syndrome patients: correlation with reduced structural integrity of acini and ducts. Arthritis Rheum 2003;48(9):2573-84.

21. Guggenheimer J, Moore PA. Xerostomia: etiology, recognition and treatment. J Am Dent Assoc 2003; 134(1):61-9; quiz 118-9.

22. Von Bültzingslöwen I, Sollecito TP, Fox PC, Daniels T, Jonsson R, Lockhart PB, et al. Salivary dysfunction associated with systemic diseases: systematic review and clinical management recommendations. Oral Surg Oral Med Oral Pathol Oral Radiol Endod 2007;103 Suppl: S57.e1-15.

23. Potthoff A, Witte T, Rifai K, Hoy L, Deterding K, Feyerabend $S$, et al. Prevalence of alpha-fodrin antibodies in patients with chronic hepatitis C infection and Sjögren syndrome. Scand J Gastroenterol 2009;44(8):994-1003.
25. Yan W, Apweiler R, Balgley BM, Boontheung P, Bundy JL, Cargile BJ, et al. Systematic comparison of the human saliva and plasma proteomes. Proteomics Clin Appl 2009;3(1):11634.

25. De Almeida Pdel V, Grégio AM, Machado MA, de Lima AA, Azevedo LR. Saliva composition and functions: a comprehensive review. J Contemp Dent Pract 2008;9(3):72-80.

26. Pedersen AM, Bardow A, Nauntofte B. Salivary changes and dental caries as potential oral markers of autoimmune salivary gland dysfunction in primary Sjögren's syndrome. BMC Clin Pathol 2005;5(1): 4.

27. Hsu S, Dickinson D. A new approach to managing oral manifestations of Sjögren's syndrome and skin manifestations of lupus. J Biochem Mol Biol 2006;39(3):229-39.

28. Astor FC, Hanft KL, Ciocon JO. Xerostomia: a prevalent condition in the elderly. Ear Nose Throat J 1999;78(7):476-9.

29. Graham J Mount, W R Hume. Conservación y Restauración de la Estructura Dental. Madrid: Edit Harcourt Brace; 1999.

30. Barbería E, Boj J R, Catalá M, García C, Mendoza A. Odontopediatría $2^{a}$ edición. Barcelona: Masson; 2002.

31. Jenson L, Budenz AW, Featherstone JD, RamosGómez FJ, Spolsky VW, Young DA. Clinical protocols for caries management by risk assessment. J Calif Dent Assoc 2007;35(10):71423.

32. Featherstone JD, Adair SM, Anderson MH, Berkowitz RJ, Bird WF, Crall JJ, et al. Caries management by risk assessment: consensus statement, April 2002. J Calif Dent Assoc 2003;31 (3):257-69.

33. Young DA, Kutsch VK, Whitehouse J. A clinician's guide to CAMBRA: a simple approach. Compend Contin Educ Dent 2009;30(2):92-4, 96, 98. 
34. Atkinson JC. Consideration oral and dental in Sjögren Syndrome. J Am Dent Assoc 1993;125: 74-86.

35. Langer A. Prosthodontic failures in patients with systemic disorders. J Oral Rehabil 1979;6(1):13-9.

36. Isidor $\mathrm{F}$, Brøndum $\mathrm{K}$, Hansen $\mathrm{HJ}$, Jensen J, Sindet-Pedersen S. Outcome of treatment with implant-retained dental prostheses in patients with Sjögren syndrome. Int J Oral Maxillofac Implants 1999;14(5):736-43.

37. Rhodus NL. Sjögren's syndrome. Quintessence Int 1999;30(10):689-99.

38. Vivino F B, Al-Hashimi I, Khan Z, LeVeque F G, Salisbury P L, Tran-Johnson T K et al. Pilocarpine Tablets for the Treatment of Dry Mouth and Dry Eye Symptoms in Patients With Sjögren Syndrome. Arch Intern Med 1999;159:174-81.

39. Petrone D, Condemi JJ, Fife R, Gluck O, Cohen S, Dalgin P. A double-blind, randomized, placebocontrolled study of cevimeline in Sjögren's syndrome patients with xerostomia and keratoconjunctivitis sicca. Arthritis Rheum 2002;46(3): 748-54.

40. Suzuki K, Matsumoto $M$, Nakashima M, Takada K, Nakanishi T, Okada M, et al. Effect of cevimeline on salivary components in patients with Sjögren syndrome. Pharmacology 2005;74(2):100-5.

41. Cummins MJ, Papas A, Kammer GM, Fox PC. Treatment of primary Sjögren's syndrome with low-dose human interferon alfa administered by the oromucosal route: combined phase III results. Arthritis Rheum 2003;49(4):585-93.
42. Khurshudian AV. A pilot study to test the efficacy of oral administration of interferon-alpha lozenges to patients with Sjögren's syndrome. Oral Surg Oral Med Oral Pathol Oral Radiol Endod 2003; 95(1):38-44.

43. Kassan SS, Moutsopoulos HM. Clinical manifestations and early diagnosis of Sjögren syndrome. Arch Intern Med 2004;164(12):127584.

44. Marton K, Boros I, Fejerdy P, Madlena M. Evaluation of unstimulated flow rates of whole and palatal saliva in healthy patients wearing complete dentures and in patients with Sjögren's syndrome. J Prosthet Dent 2004;91:577-81.

45. Barkvoll P, Rölla G, Bellagamba S. Interaction between chlorhexidine digluconate and sodium monofluorophosphate in vitro. Scand J Dent Res 1988;96(1):30-3.

46. Seymour RA. Drug interactions in dentistry. Dent Update 2009;36(8):458-60, 463-6, 469-70.

47. Fontana $M$, Zero T. Assessing patients caries risk. JADA 2006; 137:1231-39

\section{CORRESPONDENCIA}

Dra. María Angélica Torres-Quintana

Departamento de Patología

Facultad de Odontología

Universidad de Chile.

Sergio Livingstone Pohlhammer, 943

Independencia. Santiago de Chile.

E-mail:mantorre@uchile.cl 